\title{
ANALISIS KONJOIN PREFERENSI KONSUMEN SAYURAN HIDROPONIK AGROFARM BANDUNGAN KABUPATEN SEMARANG
}

\author{
T. R. Yasmin, W. D. Prastiwi, M. Handayani \\ Prodi Agribisnis, Fakultas Peternakan dan Pertanian, Universitas Diponegoro \\ Corresponding Email: talasiruqayasmin@gmail.com \\ Diterima 15 Februari 2017, disetujui 25 Maret 2017
}

\section{ABSTRAK}

Penelitian bertujuan untuk menganalisis tingkat preferensi dan urutan kepentingan konsumen terhadap sayuran hidroponik di Hidroponik Agrofarm Bandungan. Sebanyak 100 orang responden konsumen hidroponik di Agrofarm Bandungan yang merupakan konsumen lama dan baru, terpilih untuk menjawab pertanyaan dalam kuesioner. Metode penelitian yang digunakan adalah studi kasus. Metode penentuan lokasi menggunakan metode purposive. Metode penentuan responden menggunakan purposive sampling. Metode pengumpulan data dengan wawancara menggunakan kuisioner terstruktur. Data penelitian dianalisis menggunakan analisis Konjoin dengan kombinasi sebanyak $2^{4}$ atribut. Berdasarkan hasil penelitian sayuran hidroponik yang paling disukai konsumen adalah jenis Salada Locarno. Urutan preferensi kombinasi atribut sayuran hidroponik yang paling diprioritaskan oleh konsumen berturut-turut adalah fisik, warna, tingkat kesegaran, dan harga sayuran

\section{Kata kunci: Sayuran hidroponik, preferensi konsumen, analisis konjoin}

\begin{abstract}
This research was purposed to analyze the preferences of consumers who consumed hydroponic vegetables in Agrofarm Bandungan and to sort the important thing of hydroponic vegetables that consumers like the most. 100 respondents that consist of new consumer and old consumer was chosen to fill the questionnaires. Case study was used for research method. Purposive method was used to determine location. Purposive sampling was used to determine respondents. Interview method with questionnaire were used for collecting data. Data were analyzed with Conjoint analysis with $2^{4}$ combination atribute. Result showed that hydroponics vegetables that consumers like the most was Salada Locarno. Consumers priority and combination atribute in purchasing hydroponic vegetables respectively were the freshness of the vegetables, the color of vegetables, the physic of the leaves, and then the price.
\end{abstract}

Key words: hydroponic, vegetable, consumer, preferences, conjoint

\section{PENDAHULUAN}

Sayuran hidroponik adalah sayuran yang ditanam tanpa menggunakan media tanam dari tanah melainkan menggunakan media tanam air yang mengandung campuran hara
(Rosliani dan Sumarni, 2005). Terbatasnya lahan pertanian dan berkurangnya tingkat kesuburan tanah menyebabkan penurunan kualitas dan kuantitas sayuran yang diproduksi. Oleh karena itu, sayuran hidroponik merupakan salah satu solusi dari 
permasalahan tersebut.

Hidroponik Agrofarm Bandungan merupakan salah satu produsen sayuran hidroponik terbesar di Kabupaten Semarang. Hidroponik Agrofarm Bandungan menjual beberapa jenis sayuran hidroponik, antara lain hidroponik Pak Coy, Caisim, Kangkung, Bayam Hijau, Bayam Merah, Sawi Putih, Selada Lolorosa, Selada Locarno, Romaine, Kristine, Butterhead, Oakleaf, Ava, Mia, Daun Mint, dan Arugula. Pemilihan Hidroponik Agrofarm Bandungan sebagai lokasi penelitian karena merupakan perusahaan hidroponik yang pertama kali ada di Bandungan. Komoditasnya telah masuk hampir ke seluruh swalayan di Kota Semarang antara lain, Giant, Good Fellas, Gelael, dan omset yang didapatkan perbulan mencapai $\mathrm{Rp} 25.000 .000,00$, serta perkiraan konsumen dalam sebulan melebihi 200 orang. Kota Semarang merupakan peringkat 4 jumlah penduduk terbanyak di Jawa Tengah, yaitu 1.612.803 jiwa (Pemerintah Provinsi Jawa Tengah, 2013) sehingga potensi konsumen yang mengkonsumsi sayuran hidroponik besar dan cocok untuk dijadikan tempat penelitian.

Sistem pemesanan sayuran pada Hidroponik Agrofarm Bandungan menggunakan grup whatsapp. Pertama-tama pihak Agrofarm Bandungan akan melihat trend penjualan sebulan sebelumnya kemudian setelah itu ditentukan sayuran apa yang akan ditanam. Setelah panen pihak Agrofarm akan memberi informasi kepada pelanggan tetap lewat grup whatsapp dan kemudian terjadi transaksi jual beli menggunakan whatsapp. Namun, pelanggan bisa juga langsung membeli di kebun Hidroponik Agrofarm Bandungan, ataupun di kios Hidroponik Agrofarm Bandungan.

Konsumen akan memperhatikan atributatribut atau petunjuk kualitas dalam membeli sayuran, khususnya sayuran hidroponik. Informasi pasar mengenai preferensi konsumen diperlukan untuk mengetahui keinginan konsumen. Preferensi konsumen merupakan tingkat kesukaan konsumen terhadap suatu produk tertentu dibandingkan produk lain (Kotler, 1997). Preferensi konsumen dapat menyediakan apa keinginan dan kebutuhan konsumen. Oleh karena itu, penelitian tentang hal ini penting untuk dilakukan.

Tujuan dari penelitian ini adalah untuk mengidentifikasi bagaimana preferensi konsumen sayuran hidroponik. Manfaat dari penelitian ini diharapkan dapat memberikan informasi tentang preferensi konsumen sayuran hidroponik serta keinginan dan kebutuhan konsumen sayuran hidroponik bagi perusahaan ataupun yang berkaitan dengan komonitas sejenis bagi pihak lain.

\section{METODE PENELITIAN}

Penelitian dilaksanakan pada bulan Oktober - November 2016 di Hidroponik Agrofarm Bandungan Kabupaten Semarang. Metode penelitian yang digunakan adalah studi kasus, yaitu strategi penelitian yang menyelidiki suatu program, peristiwa, aktivitas, proses atau sekelompok individu secara cermat (Creswell, 2010).

Penentuan lokasi penelitian menggunakan metode purposive, yaitu metode penentuan lokasi yang disesuaikan dengan tujuan penelitian (Usman dan Akbar, 2003). Lokasi yang dipilih adalah Kebun Hidroponik Agrofarm Bandungan Kabupaten Semarang karena lokasi tersebut memiliki dan memasarkan sayuran hidroponik.

Penentuan responden menggunakan metode purposive sampling, yaitu metode yang sesuai dengan tujuan penelitian. Responden penelitian adalah orang dewasa yang bertanggung jawab atas belanja pangan rumah tangga, yang membeli sayuran hidroponik di Hidroponik Agrofarm Bandungan. Tercatat 200 pelanggan tetap yang mengkonsumsi sayuran hidroponik hanya dipilih sample sebanyak 100 pelanggan tetap.

Analisis data menggunakan analisis Konjoin Metode analisis Konjoin dapat dijelaskan sebagai berikut (Malhotra, 2004):

$\mathrm{U}(\mathrm{X})=$

Keterangan: 
$\mathrm{U}(\mathrm{X})=$ total nilai atau utilitas

ij = nilai kegunaan taraf ke-j atribut ke-i

$\mathrm{ki}=$ banyaknya taraf dari atribut ke-i

$\mathrm{m}$ = banyaknya atribut

xij = peubah boneka atribut ke-i taraf ke-j

Kombinasi atribut yang digunakan adalah sebanyak $2^{4}$ dengan 4 atribut dan 2 taraf kombinasi. Kombinasi atribut tersebut diolah dalam bentuk kartu analisis konjoin yang memuat atribut dan taraf atribut berturut-turut sebagai berikut: kesempurnaan fisik: daun besar atau daun kecil tidak berlubang, tingkat kesegaran: sedang atau lama, warna daun: lebih muda atau lebih tua, dan harga: $<5000$ atau $>5000$. Kartu analisis konjoin yang digunakan dapat dilihat pada Ilustrasi 1.

\section{HASIL DAN PEMBAHASAN}

\section{Karakteristik Responden}

Berdasarkan Tabel 1 diperoleh bahwa 58\% konsumen sayuran hidroponik berjenis kelamin laki-laki. Pada umumnya laki-laki di Indonesia merupakan tulang punggung keluarga yang bertanggung jawab mencari nafkah. Hal ini berbeda dengan hasil penelitian Hidayati (2014) tentang preferensi sayuran organik yang menemukan bahwa $92 \%$ perempuan lebih banyak yang membeli sayuran organik karena perempuan merupakan pengambil keputusan dalam konsumsi rumah tangga. Responden yang berumur $>49$ tahun sebesar $25 \%$ lebih banyak mengkonsumsi sayuran hidroponik (Tabel 1).

Berdasarkan Tabel 1 dapat dijelaskan bahwa semakin bertambahnya umur seseorang maka konsumen akan semakin loyal dan berhati-hati dalam memilih produk yang dibelinya (Solomon et al., 2006). Hal ini mengkonfirmasi penelitian Hariyani (2009) mengenai sayuran bebas residu menyebutkan bahwa konsumen yang mengkonsumsi sayuran bebas residu lebih banyak yang berusia $>49$ tahun karena pada usia tersebut konsumen lebih peduli tentang masalah kesehatan. Kisaran jumlah anggota keluarga responden sebesar 56\% adalah sebesar $3-4$ orang (Tabel 1). Pada umumnya jumlah keluarga ideal di Indonesia terdiri atas ayah, ibu, dan 2 orang anak. Pada penelitian Hariyani (2009) dan Hasibuan (2013) mengenai sayuran bebas residu pestisida menemukan hal yang sama, yaitu sayuran bebas residu pestisida banyak dikonsumsi oleh keluarga dengan jumlah anggota sebesar 4 orang.

Tingkat pendidikan tertinggi pada Tabel 1 adalah S1 dengan persentase sebesar 57\% dan tingkat pendidikan terendah adalah SMP dengan persentase sebesar 3\%. Semakin tinggi tingkat pendidikan seseorang maka informasi yang dimiliki semakin banyak, semakin selektif pula dalam memilih sebuah produk yang dikonsumsi (Noel, 2009). Tingkat pendidikan yang tinggi akan memberi pengetahuan nilai gizi yang terkandung dan pengaruhnya terhadap kesehatan yang akan mempengaruhi keputusan pembelian seorang konsumen. Hal ini sesuai dengan penelitian Hariyani (2009) mengenai sayuran bebas residu yang menyatakan bahwa konsumen sayuran bebas residu lebih banyak berpendidikan D3/Perguruan Tinggi karena tingkat pendidikan berpengaruh dalam

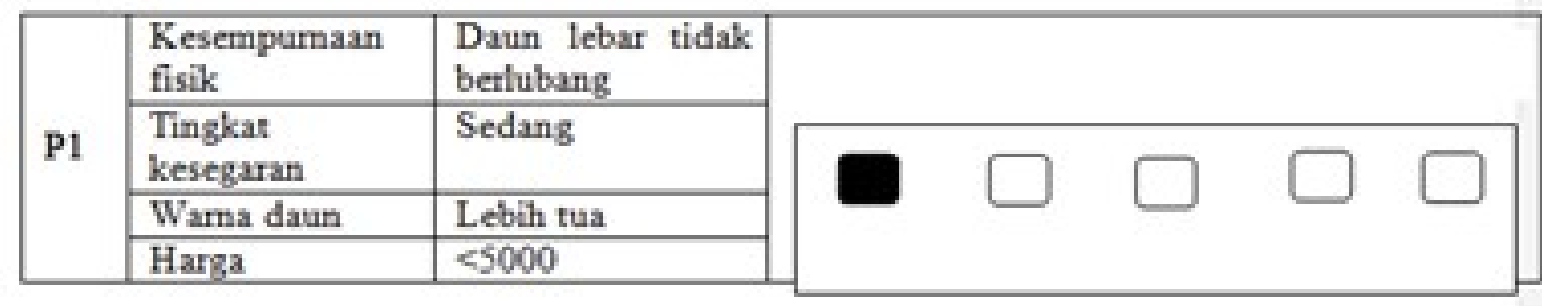

Ilustrasi 1. Contoh Kartu Analisis Konjoin

Desain kartu diadaptasi dari penelitian Kusumawati (2011) 
Tabel 1. Karakteristik Responden Konsumen Hidroponik Agrofarm

\begin{tabular}{|c|c|}
\hline Karakteristik & Persentase \\
\hline & --- $(\%)$--- \\
\hline \multicolumn{2}{|l|}{ Jenis Kelamin } \\
\hline - Perempuan & 42,0 \\
\hline - Laki-laki & 58,0 \\
\hline \multicolumn{2}{|l|}{ Kelompok Umur (Tahun) } \\
\hline$-18-25$ & 14,0 \\
\hline$-26-33$ & 20,0 \\
\hline$-34-41$ & 22,0 \\
\hline$-42-49$ & 19,0 \\
\hline - >49 & 25,0 \\
\hline \multicolumn{2}{|l|}{ Jumlah Anggota Keluarga } \\
\hline (Orang) & 18,0 \\
\hline-1 & 14,0 \\
\hline-2 & \\
\hline-3 & 24,0 \\
\hline-4 & 32,0 \\
\hline$->5$ & 12,0 \\
\hline \multicolumn{2}{|l|}{ Tingkat Pendidikan } \\
\hline - SMP & 3,0 \\
\hline - SMA & 23,0 \\
\hline - D3 & 9,0 \\
\hline - S1 & 57,0 \\
\hline - S2 & 6,0 \\
\hline$-\mathrm{S} 3$ & 2,0 \\
\hline \multicolumn{2}{|l|}{ Tempat Pembelian Sayuran } \\
\hline \multicolumn{2}{|c|}{ Hidroponik Selain Di Agrofarm } \\
\hline - Superindo & 27,6 \\
\hline - Giant & 12,7 \\
\hline - Carefour & 5,2 \\
\hline - Gelael & 25,4 \\
\hline - Hero & 3,7 \\
\hline - Lainnya & 25,4 \\
\hline \multicolumn{2}{|l|}{ Alasan Membeli Sayuran } \\
\hline Hidroponik & 92,3 \\
\hline - Untuk dikonsumsi & 3,8 \\
\hline $\begin{array}{l}\text { - Untuk ditanam kembali } \\
\text { - Lainnya }\end{array}$ & 3,8 \\
\hline
\end{tabular}

Sumber: data primer penelitian terolah (2016)

pengambilan keputusan pembelian.

Tempat pembelian sayuran hidroponik yang paling sering didatangi konsumen adalah Superindo dengan persentase sebesar $27,6 \%$ (Tabel 1), dan yang terendah adalah Hero dengan persentase sebesar 3,7\% (Tabel 1). Hal ini sesuai dengan penelitian Delita (2008) yang menyatakan bahwa konsumen lebih menyukai berbelanja di tempat yang nyaman dengan persentase $96,67 \%$ konsumen memilih membeli dengan mengutamakan sayuran segar di tempat yang nyaman.

Alasan terbanyak responden membeli sayuran hidroponik adalah untuk dikonsumsi dengan presentase jumlah responden yang menjawab sebesar 92,3\% (Tabel 1), dan sisanya untuk ditanam kembali serta lainnya (karena sehat, bebas pestisida, segar) dengan persentase masing-masing 3,8\% (Tabel 1). Hal ini bersesuaian dengan penelitian Bentarjani (2013) mengenai sayuran organik, yang menyatakan bahwa konsumen lebih memilih sayuran organik karena lebih sehat dan aman untuk dikonsumsi dibandingkan untuk ditanam kembali.

Pendapatan responden pada Tabel 2 dapat dibedakan menjadi 3 kelas pendapatan, yaitu $<\mathrm{Rp} 1.000 .000,00$ dan $\mathrm{Rp} 1.000 .000,00$ - Rp 2.500.000,00 termasuk kelas menengah kebawah, Rp 2.500.001,00 - Rp 5.000.000,00 termasuk kelas menengah, Rp 5.000.000,00 $\mathrm{Rp} 10.000 .000,00$ dan > Rp 10.000.000,00 termasuk kelas menengah keatas. Klasifikasi pendapatan ini mengacu pada BPPK Kementrian Keuangan (2015).

Frekuensi konsumsi sayuran hidroponik terbanyak adalah sebesar $47 \%$ adalah $1-2$ kali/ minggu, tetapi $15 \%$ konsumen mengkonsumsi sayuran hidroponik $>7$ kali/minggu, dengan persentase $23 \%$ konsumen memiliki pendapatan Rp $5.000 .000,00-\mathrm{Rp} 10.000 .000,00 /$ bulan dan $21 \%$ konsumen memiliki pendapatan $>\mathrm{Rp}$ $10.000 .000,00 /$ bulan dengan total responden menengah keatas adalah 44\%. Hal ini sesuai dengan Penelitian Maswadi (2012) mengenai perilaku konsumen terhadap sayur organik menemukan bahwa konsumen yang memiliki pendapatan $>$ Rp 1.500.000,00 lebih banyak melakukan pembelian sayuran organik, yaitu 10 kali dalam sebulan, yang artinya semakin tinggi tingkat pendapatan konsumen maka semakin tinggi minat konsumen untuk mengkonsumsi sayuran organik.

Pengeluaran konsumsi terbanyak untuk membeli sayuran hidroponik dalam seminggu (Tabel 2) adalah antara $\mathrm{Rp} 20.000,00-\mathrm{Rp}$ $30.000,00 /$ minggu dengan persentase sebesar 
Tabel 2. Tabulasi Silang antara Pendapatan, Pengeluaran, dan Frekuensi Konsumsi Responden

\begin{tabular}{|c|c|c|c|c|c|c|c|}
\hline \multirow[t]{2}{*}{ No. } & \multirow[t]{2}{*}{ Karakteristik } & \multicolumn{5}{|c|}{$\begin{array}{c}\text { Frekuensi Konsumsi Sayuran Hidroponik } \\
\text { Seminggu }\end{array}$} & \multirow[t]{2}{*}{ Total (\%) } \\
\hline & & $1-2$ & $3-4$ & $5-6$ & $>7$ & Lainnya & \\
\hline \multirow[t]{14}{*}{1.} & Pendapatan Responden (Rp) & & & & & & \\
\hline & - Strata 1 & 4 & 1 & 0 & 0 & 2 & 7 \\
\hline & - Strata 2 & 14 & 4 & 1 & 1 & 0 & 20 \\
\hline & - Strata 3 & 16 & 9 & 0 & 4 & 0 & 29 \\
\hline & - Strata 4 & 7 & 3 & 6 & 7 & 0 & 23 \\
\hline & - Strata 5 & 6 & 9 & 2 & 3 & 1 & 21 \\
\hline & Total $(\%)$ & 47 & 26 & 9 & 15 & 3 & 100 \\
\hline & Pengeluaran Perminggu (Rp) & & & & & & \\
\hline & - Strata A & 9 & 1 & 0 & 0 & 2 & 12 \\
\hline & - Strata B & 25 & 10 & 0 & 1 & 0 & 36 \\
\hline & - Strata C & 5 & 8 & 1 & 2 & 1 & 17 \\
\hline & - Strata D & 4 & 1 & 1 & 1 & 0 & 7 \\
\hline & - Strata E & 4 & 6 & 7 & 11 & 0 & 28 \\
\hline & Total (\%) & 47 & 26 & 9 & 15 & 3 & 100 \\
\hline
\end{tabular}

Sumber: data primer penelitian terolah (2016)

Keterangan :

Strata 1: $\mathrm{Rp}<1.000 .000,00$

Strata 2: Rp 1.000.001,00-2.500.000,00

Strata 3: Rp 2.500.001,00-5.000.000,00

Strata A: Rp $<20.000,00$

Strata 4: Rp 5.000.001,00-10.000.000,00

Strata 5: $\mathrm{Rp}>10.000 .000,00$

Strata B: Rp 20.000,00 - 30.000,00

Strata C: Rp 30.001,00-40.000,00

Strata D: Rp 40.001,00 - 50.000,00

Strata E: Rp $>50.000,00$

36\%. Hal ini dapat diartikan bahwa dalam sebulan pengeluaran konsumsi sayuran hidroponik berkisar antara Rp 80.000,00 - Rp $120.000,00 /$ bulan dengan pembelian terbanyak $1-2$ kali perminggu. Banyak atau sedikitnya jumlah pengeluaran seorang konsumen tergantung tingkat pendapatan dan jumlah keluarga. Hasil penelitian ini hasil berbeda dengan data konsumsi sayuran organik penelitian Mujahidah (2013) di Bogor yang menemukan bahwa pengeluaran responden sayuran organik terbanyak pertama sebesar 31\% berkisar antara $\mathrm{Rp} 40.000,00-$ $\mathrm{Rp} 50.000,00 /$ bulan, kemudian terbanyak kedua sebesar $23 \%$ berkisar antara $\mathrm{Rp}$ $50.000,00$ - Rp 100.000,00 dan terbanyak ketiga sebesar $18 \%>$ Rp 100.000,00. Hal ini dapat terjadi karena perbedaan harga dan ragam pembelian sayur organik dan sayur hidroponik per konsumen di wilayah yang berbeda dengan tingkat pendapatan masyarakat yang berbeda.

\section{Preferensi Konsumen Sayuran Hidroponik}

Jenis sayuran hidroponik yang sering dikonsumsi konsumen dapat dilihat pada Tabel 3. Sebanyak 100 responden memilih jenis sayuran hidroponik lebih dari 2 sayuran sehingga urutan sayuran hidroponik yang disukai konsumen dari 1 sampai 5 adalah Salada Locarno, Pak Coy, Kangkung, Salada Romaine, dan Caisim, dengan total persentase $58,1 \%$. Sebesar $41,9 \%$ lainnya terdiri dari 11 sayuran dengan rata-rata $3.8 \%$ konsumen memilih sayuran tersebut (Tabel 3). Hal ini berbeda dengan hasil penelitian Evangelo (2010) mengenai salada di California yang menemukan bahwa konsumen lebih menyukai salada Romaine dengan persentase $41,7 \%$ dibandingkan jenis salada yang lainnya. Hasil analisis Konjoin mengenai preferensi sayuran hidroponik di Agrofarm Bandungan dapat dilihat pada Tabel 4.

Komponen fisik daun yang lebar tidak berlubang sesuai dengan Tabel 4 memiliki 
nilai utilitas positif 0,071 artinya konsumen lebih menyukai daun yang memiliki fisik lebar dan tidak berlubang dibanding daun yang kecil dan tidak berlubang. Kesegaran yang kurang dari 6 hari juga memiliki nilai utilitas positif, yaitu 0,276 artinya konsumen lebih menyukai kesegaran sayuran yang kurang dari 6 hari dibanding yang lebih dari 6 hari, walaupun pelanggan Agrofarm Bandungan sudah mengetahui bahwa sayuran hidroponik bisa bertahan $>6$ hari apabila diletakkan dalam kulkas. Warna daun yang disukai konsumen adalah warna daun lebih muda dengan nilai utilitas positif, yaitu 0,154 dibandingkan warna daun yang lebih tua. Harga yang lebih disukai konsumen adalah kurang dari Rp 5.000,00 dengan nilai utilitas positif sebesar 0,136. Artinya secara keseluruhan konsumen lebih menyukai sayuran hidroponik yang memiliki fisik daun lebar dan tidak berlubang, tingkat kesegaran kurang dari 6 hari, warna daun lebih muda, dan harga yang kurang dari $\mathrm{Rp} 5.000,00$. Menurut Santoso (2012) nilai utility merupakan selisih antara nilai rata-rata faktor tertentu dengan nilai constant sebagai penentu positif atau negatif pada nilai utility. Urutan kepentingan (importance value) terhadap atribut sayuran hidroponik dapat dilihat pada Tabel 5.

Pada Tabel 5 terlihat atribut sayuran hidroponik yang paling penting pertama adalah kesegaran sayuran $(34,410 \%)$, kedua adalah warna daun $(24,468 \%)$, ketiga adalah fisik daun $(20,546 \%)$ dan keempat adalah harga $(19,576 \%)$. Hal ini sedikit berbeda dengan penelitian Hariyani (2009) mengenai sayuran bebas residu yang menyatakan bahwa tingkat kepentingan konsumen dari tingkat tertinggi hingga terendah adalah rasa, kesegaran sayuran, kesempurnaan fisik, warna sayuran, kemasan sayuran dan harga sayuran. Perbedaan ini karena atribut rasa dan kemasan tidak diteliti pada penelitian ini.

\section{Atribut Kesegaran Sayuran}

Atribut kesegaran sayuran memiliki nilai importance value sebesar 34,410\% (Tabel 5). Hal ini berarti konsumen lebih mengutamakan atribut kesegaran sayuran dibanding atribut lainnya. Menurut penelitian terdahulu yang dilakukan oleh Dasipah et al. (2010) mengenai perilaku konsumen produk sayuran menyatakan bahwa konsumen lebih menyukai sayuran yang memiliki kandungan vitamin yang baik, kesegaran yang terlihat, dan sayuran yang cara pembersihannya tidak merepotkan.

Pada taraf atribut kesegaran sayuran, konsumen lebih memilih tingkat kesegaran yang kurang dari 6 hari. Sebagian responden mengatakan lebih memilih kesegaran yang kurang dari 6 hari karena biasanya sebelum 6 hari sayuran yang mereka beli sudah habis dikonsumsi, sehingga tidak sampai lama disimpan. Menurut penelitian Hariyani (2009) mengenai sayuran bebas residu, konsumen lebih menyukai tingkat kesegaran antara $2-3$ hari dibanding kurang dari 2 hari.

\section{Atribut Warna Daun}

Warna daun merupakan prioritas kedua yang menjadi pertimbangan konsumen dalam memilih sayuran hidroponik. Nilai kepentingan relatifnya adalah sebesar 24,468\% (Tabel 5). Atribut warna disini adalah indikator seorang konsumen jika memilih suatu sayuran hidroponik lebih tertarik membeli warna yang lebih muda atau lebih tua dengan tidak memperhatikan jenis dari sayuran itu sendiri. Pada taraf atribut

Tabel 3. Jenis Sayuran Hidroponik yang Sering Dikonsumsi

\begin{tabular}{lcc}
\hline \hline $\begin{array}{c}\text { Jenis Sayuran } \\
\text { Hidroponik }\end{array}$ & $\begin{array}{c}\text { Frekuensi } \\
\text { Pemilihan }\end{array}$ & $\begin{array}{c}\text { Persentase } \\
(\%)\end{array}$ \\
\hline Salada Locarno & 49 & 13,9 \\
Pak Coy & 48 & 13,6 \\
Kangkung & 47 & 13,3 \\
Salada Romaine & 31 & 8,8 \\
Caisim & 30 & 8,5 \\
Lainnya & 148 & 41.9 \\
\hline Jumlah & 353 & 100 \\
\hline
\end{tabular}

Sumber: data primer penelitian terolah (2016)

warna, konsumen lebih memilih warna daun yang lebih muda karena warna sayuran muda lebih menarik dan lebih enak dikonsumsi. Pada penelitian Delita (2008) mengenai perilaku konsumen sayuran segar, konsumen 
Tabel 4. Hasil Analisis Konjoin

\begin{tabular}{llcc}
\hline & Keterangan & Utility Estimate & Std. Error \\
\hline Fisik daun & Lebar tidak berlubang & 0,071 & 0,029 \\
& Kecil tidak berlubang & $-0,071$ & 0,029 \\
Kesegaran & $<6$ hari & 0,276 & 0,029 \\
& $>$ Whari & $-0,276$ & 0,029 \\
Warna & Tua & $-0,154$ & 0,029 \\
& Muda & 0,154 & 0,029 \\
& $>5000$ & $-0,136$ & 0,029 \\
(Constant) & $<5000$ & 0,136 & 0,029 \\
\hline
\end{tabular}

Sumber: data primer penelitian terolah (2016)

lebih menyukai warna sayuran lebih cerah dan lebih bersih, hal tersebut dapat menjadi alasan utama konsumen membeli sayuran tersebut.

\section{Atribut Fisik Daun}

Nilai kepentingan relatif atribut fisik daun adalah sebesar 20,546\% (Tabel 5) yang berada pada urutan ketiga dalam atribut preferensi sayuran hidroponik. Sebagian besar konsumen lebih memilih fisik daun yang lebar dan tidak berlubang karena jumlah yang dikonsumsi akan lebih banyak dibandingkan daun yang kecil. Hal ini sesuai dengan penelitian Hariyani (2009) mengenai sayuran bebas residu, menyatakan bahwa konsumen lebih memilih sayuran yang memiliki daun yang lebar dan tidak berlubang. Penelitian Hariyani (2009) juga menemukan bahwa fisik daun pada urutan ketiga setelah kualitas dan kesegaran sayuran.

\section{Harga}

Pada penelitian ini harga merupakan atribut paling akhir yang diperhatikan oleh responden konsumen sayuran hidroponik. Tidak ada perbandingan harga terkait fisik daun dan kesegaran. Walaupun fisik kecil atau besar harga akan tetap sama, begitu juga dengan kesegaran tidak terkait dengan harga karena harga yang dipatok adalah per pieces sayuran dan tidak tergantung oleh fisik atau kesegaran.

Nilai kepentingan relatif harga adalah sebesar 19,576\% (Tabel 5) yang merupakan urutan terakhir dalam atribut preferensi sayuran hidroponik. Harga yang dipatok pada penelitian ini karena harga jual Agrofarm adalah (Rp 4000)/pcs atau $(<\mathrm{Rp} 5000)$ dan dibandingkan dengan harga superindo adalah Rp 5080/pcs atau (>5000). Harga merupakan atribut yang menjadi urutan terakhir karena sebagian besar konsumen hidroponik berada pada kalangan menengah, dan berpendidikan tinggi yang sudah mengetahui informasi tentang sayuran hidroponik, baik gizi yang

Tabel 5. Importance Value Sayuran Hidroponik

\begin{tabular}{lc}
\hline \hline \multicolumn{1}{c}{ Atribut } & $\begin{array}{c}\text { Persentase } \\
(\%)\end{array}$ \\
\hline Fisik Daun & 20,546 \\
Kesegaran Sayuran & 34,410 \\
Warna Daun & 24,468 \\
Harga & 19,576 \\
\hline \multicolumn{2}{l}{ Sumber: data primer penelitian terolah (2016) }
\end{tabular}

terkandung, higienitas, kesegaran, maupun kualitasnya yang lebih sehat. Hal ini sesuai dengan pendapat Pua et al. (2014) yang menyatakan bahwa pendapatan konsumen dengan kesadaran konsumen membeli sayuran bebas pestisida berbanding lurus, apabila konsumen memiliki pendapatan tinggi maka konsumen cenderung membeli sayuran bebas pestisida secara rutin.

Responden lebih memilih memilih harga pada taraf atribut kurang dari Rp 5.000,00 karena harga tersebut sangat terjangkau bagi konsumen hidroponik. Konsumen dengan pendapatan tinggi saat melakukan pembelian sayuran tidak keberatan dengan harga yang 
mereka bayar karena sepadan dengan mutu dan kebersihan yang didapatkan. Hal ini sesuai dengan penelitian Hariyani (2009) yang menyatakan bahwa konsumen lebih menyukai harga sayuran yang kurang dari $\mathrm{Rp}$ 5.000,00. Penelitian Dasipah (2010) menambahkan bahwa konsumen saat melakukan pembelian sayuran tidak keberatan dengan harga yang mereka bayar karena sepadan dengan mutu dan kebersihan yang didapatkan.

\section{KESIMPULAN DAN SARAN}

Berdasarkan hasil penelitian mengenai preferensi konsumen sayuran hidroponik di Agrofarm Bandungan, dapat diambil beberapa kesimpulan, antara lain: (1) Jenis sayuran hidroponik yang paling disukai konsumen adalah Salada Locarno dengan preferensi kombinasi atribut fisik daun lebar dan tidak berlubang, warna daun muda, tingkat kesegaran sayuran kurang dari 6 hari, dan harga sayuran kurang dari Rp 5.000,00 dan jenis yang paling. (2). Berdasarkan urutan kepentingan relatif yang paling diprioritaskan oleh konsumen berturut-turut dalam membeli sayuran hidroponik adalah kesegaran sayuran, warna daun, fisik daun, dan harga.

Saran untuk penelitian selanjutnya diharapkan dapat memberikan gambaran secara spesifik untuk semua sayuran hidroponik karena setiap jenis sayuran hidroponik berbeda ukuran daun dan warnanya, namun dalam penelitian ini belum terlalu dibahas secara spesifik.

\section{DAFTAR PUSTAKA}

Badan Pendidikan dan Pelatihan Keuangan Kementrian Keuangan. 2015. Penghasilan Kelas Menengah Naik? = Potensi Pajak. (http://www.bppk.kemenkeu.go.id/publikasi/artikel/167-artikelpajak/21014-penghasilan-kelas-menengah-naik-potensi-pajak). Tanggal diakses 15 Desember 2016.

Bentarjani, F. M. P. 2013. Analisis Tipe Perilaku Konsumen Sayuran Organik Di
Pasar Swalayan Kabupaten Sidoarjo. Skripsi. Solo: Fakultas Pertanian Universitas Surakarta.

Creswell, John W. 2010. Research Design Pendekatan Kualitatif, Kuantitatif, dan Mixed. Diterjemahkan oleh: Achmad Fawaid. Pustaka Pelajar, Yogyakarta.

Dasipah, E., H. Budiyono, dan M. Julaeni. 2010. Analisis perilaku konsumen dalam pembelian produk sayuran di pasar modern kota bekasi. J. Agribisnis dan Pengembangan Wilayah. 1(2): $24-37$.

Delita, N. 2008. Analisis Perilaku Konsumen Sayuran Segar Pada Supermarket Foodmart Di Plaza Ekalokasari Bogor. Skripsi. Bogor: Fakultas Pertanian Institut Pertanian Bogor.

Evangelo, J. D. 2010. A Target Profile and Positioning for an Informational Lettuce Website. Skripsi. California: Fakultas Pertanian Universitas Politeknik California.

Hariyani, A.L. 2005. Analisis Preferensi Konsumen Terhadap Sayuran Bebas Residu Pestisida. Skripsi. Solo: Fakultas Pertanian Universitas Surakarta.

Hasibuan, N. T. 2008. Analisis Faktor Yang Mempengaruhi Konsumen Akan Sayur Organik. Skripsi. Medan: Fakultas Pertanian Universitas Sumatera Utara

Hidayati, N. 2014. Preferensi Konsumen Dan Pengaruh Kualitas Produk Sayuran Organik Terhadap Kepuasan Konsumen Dalam Membentuk Loyalitas Pelanggan. Thesis. Bogor: Fakultas Pertanian Institut Pertanian Bogor.

Kotler, P. 1997. Manajemen Pemasaran. Diterjemahkan oleh: Hendra Teguh, Ronny Rusly, dan Benjamin Molan. Prenhalindo, Jakarta.

Kusumawati, A. 2011. Understanding student choice criteria for selecting an indonesian public university: a conjoint analysis approach. SBS HDR Student Conference. Hal: 16.

Malhotra, N.K. 2004. Marketing Research: An Applied Orientation. 4th Ed, Pearson Education Inc, New Jersey.

Maswadi. 2012. Kajian faktor kepribadian 
perilaku konsumen terhadap pembelian sayur organik di supermarket Kota Pontianak. J. Eksos. 8(1): 1-8.

Mujahidah, K. 2013. Analisis Faktor dan Proses Pengambilan Keputusan Pembelian Sayuran Organik di Yogya Bogor Junction. Skripsi. Bogor: Fakultas Pertnanian Institut Pertanian Bogor.

Noel, H. 2009. Consumer Behaviour. AVA Publishing SA, Switzerland.

Pemerintah Provinsi Jawa Tengah. 2013. Jumlah Penduduk Jawa Tengah Tahun 2013. Pemerintah Provinsi Jawa Tengah, Semarang. (http://nakertransduk.jatengprov.go.id/index.php/page/details/page13 79310736/jumlah-penduduk-jawatengah-tahun-2013.html). Tanggal di akses: 26 April, 2016.

Pua, C. O., J. Tatuh, dan V. R. B. Moniaga.
2014. Persepsi konsumen sayuran di Kota Manado terhadap produk sayuran bebas pestisida. J. Sosek FP Sam Ratulangi Manado.:1-14.

Rosliani, R dan N. Sumarni. 2005. Budidaya Tanaman Sayuran dengan Sistem Hidroponik. Balai Penelitian Tanaman Sayuran, Bandung.

Santoso, S. 2012. Aplikasi SPSS pada Statistik Multivariat. PT. Elex Media Komputindo, Jakarta.

Solomon, M., G. Bamossy., S. Askegaard., dan M. K. Hogg. 2006. Consumer Behaviour A European Perspective. $3^{\text {rd }}$ Ed, Pearson Education Limited, New Jersey.

Usman, H. dan P.S Akbar. 2003. Metodologi Penelitian Sosial. Jakarta: Bumi Aksara. 